\title{
Vestibular Physiotherapy and Yoga in Vasovagal Syndrome: case report
}

\author{
Fisioterapia Vestibular e Ioga na Síndrome Vasovagal: relato de caso \\ Fisioterapia Vestibular y Ioga en el Síndrome Vasovagal: reporte de caso
}

Received: 11/26/2020 | Reviewed: 03/12/2020 | Accept: 01/20/2021 | Published: 01/25/2021

Maria Das Graças de Araújo Lira

ORCID: https://orcid.org/0000-0001-9265-9731

Federal University of Rio Grande do Norte, Brazil

E-mail: maria.galira@gmail.com

Raysa Vanessa de Medeiros Freitas

ORCID: https://orcid.org/0000-0002-5291-4045

Federal University of Rio Grande do Norte, Brazil

E-mail: raysafreitas@hotmail.com

Wildna Sharon Martins da Costa

ORCID: https://orcid.org/0000-0003-2130-2625

Federal University of Rio Grande do Norte, Brazil

E-mail:wildnacosta@outlook.com

Henrique de Paula Bedaque

ORCID: https://orcid.org/0000-0003-4674-3056

Federal University of Rio Grande do Norte, Brazil E-mail: drbedaque@gmail.com

Maria Clara Silva de Melo

ORCID: https://orcid.org/0000-0002-8980-8043

Federal University of Rio Grande do Norte, Brazil E-mail: claramelo.maria@gmail.com

Lidiane Maria de Brito Macedo Ferreira

ORCID: https://orcid.org/0000-0002-2191-8641

Federal University of Rio Grande do Norte, Brazil E-mail: lidianembm@yahoo.com.br

Karyna Myrelly Oliveira Bezerra de Figueiredo Ribeiro

ORCID: https://orcid.org/0000-0002-5935-6760

Federal University of Rio Grande do Norte, Brazil E-mail: karynamy@hotmail.com

\begin{abstract}
This study aimed to report the effects of vestibular physiotherapy (VP) associated with Yoga in a vasovagal syndrome (VVS) patient with dizziness and body imbalance complaints. We described a 22-year-old patient who underwent one year of VP with a frequency of one to two times per week (totaling 31 sessions). The treatment for the cervical region was performed using manual therapy and motor control training of the deep cervical flexor muscles. The patient started to practice Yoga three months after the beginning of the VP. After one year of treatment, a substantial improvement in the symptoms of dizziness and postural balance were observed. However, the cervical pain remained present and cervical mobility was slightly limited after two years. These findings lasted one year after the end of the VP program, a period in which the patient performed only Yoga. Despite the promising results, future studies with larger sample sizes and adequate methodological quality are necessary to confirm the effects of therapeutic exercises in individuals with VVS.
\end{abstract}

Keywords: Vestibular physiotherapy; Vasovagal syndrome; Yoga.

\section{Resumo}

Este estudo objetivou relatar os efeitos da Fisioterapia Vestibular (FV) associada à Ioga em uma paciente com Síndrome Vasovagal (SVV) e queixa de tontura e desequilíbrio corporal. Tratou-se da descrição de um caso de uma paciente de 22 anos que realizou um ano de FV, totalizando 31 sessões numa frequência de uma a duas vezes por semana. Adicionalmente, foi realizado tratamento para a região cervical por terapia manual e treino de controle motor dos músculos flexores profundos. A paciente também passou a praticar Ioga concomitante três meses após o início da FV. Após um ano de tratamento, observou-se que a sintomatologia da tontura, bem como o equilíbrio postural melhoraram substancialmente. No entanto, o quadro álgico cervical continuou presente e a mobilidade cervical permaneceu com discreta limitação na terceira avaliação. Esses achados perduraram ainda um ano após o término das sessões, quando a paciente continuou a realizar apenas a Ioga. Apesar de resultados promissores, faz-se necessária a realização de pesquisas futuras com número amostral maior e adequada qualidade metodológica, a fim de confirmar o efeito das intervenções por exercícios terapêuticos na população com SVV.

Palavras-chave: Fisioterapia vestibular; Síndrome vasovagal; Ioga. 


\begin{abstract}
Resumen
Este estudio tuvo como objetivo informar los efectos de la fisioterapia vestibular (FV) asociados con el yoga en un paciente con síndrome vasovagal (SVV) y quejas de mareos y desequilibrio corporal. Se trataba de la descripción de un caso de un paciente de 22 años que se sometió a un año de FV, totalizando 31 sesiones con una frecuencia de una a dos veces por semana. Además, el tratamiento de la región cervical se realizó mediante terapia manual y entrenamiento de control motor de los músculos flexores profundos. El paciente también comenzó a practicar Yoga simultáneamente tres meses después del inicio de la FV. Después de un año de tratamiento, se observó que los síntomas del mareo, así como el equilibrio postural, mejoraron sustancialmente. Sin embargo, el dolor cervical permaneció presente y la movilidad cervical se mantuvo con una ligera limitación en la tercera evaluación. Estos hallazgos perduraron un año después del final de las sesiones, cuando el paciente continuó haciendo solo Yoga. A pesar de los resultados prometedores, es necesario realizar futuras investigaciones con mayor tamaño muestral y adecuada calidad metodológica, con el fin de confirmar el efecto de las intervenciones para ejercicios terapéuticos en la población con SVV.
\end{abstract}

Palabras clave: Fisioterapia vestibular; Síndrome vasovagal; Yoga.

\title{
1. Introduction
}

The vasovagal syncope or syndrome (VVS) is characterized by a transient loss of consciousness due to sudden cerebral hypoperfusion. With a higher prevalence among women, the VVS has a short duration and spontaneous recovery and can be triggered by orthostatic or emotional stress. (Brignole et al., 2018; Ganzeboom et al., 2006; Moya et al., 2009). Despite the good prognosis, it leads to a reduced quality of life, especially in older individuals with recurrent episodes and comorbidities. (Van Dijk et al., 2007). Several prodromal symptoms are associated with VVS, such as dizziness, visual turbidity, sweating, nausea, vomiting, pallor, and abdominal discomfort. (Alboni, 2015). The health costs related to VVS are similar to other chronic diseases, such as acquired immunodeficiency syndrome and chronic obstructive pulmonary disease. (Kenny, Bhangu, \& King-Kallimanis, 2013). The VVS, also known as neurocardiogenic, is one of the most common causes of syncope and presents complex pathophysiology characterized by vagal activation and sympathetic inhibition. (Mathias, Deguchi, \& Schatz, 2001). Bradycardia and/or vasodilation (i.e., the main vagal response) are related to intracardiac mechanoreceptor activation. Hemodynamic conditions (reduced venous return, low peripheral resistance, and increased myocardial contractility) and psychological factors (anxiety, depression, and fear) can also lead to VVS. (Fenton et al., 2000; Gracie et al., 2006).

The symptoms in most patients are of mild and low recurrence; thus, according to the European Society of Cardiology, the treatment is essentially non-pharmacological, including lifestyle changes, education on the benign course of the disease, recognition of prodromal symptoms and avoidance of conditions that may trigger the syncope. (Brignole et al., 2018). However, approximately $20-30 \%$ of the patients present severe symptoms or high recurrence, whose treatment becomes important. (Soteriades et al., 2002).

To date, there is no robust evidence regarding effective therapeutic measures, (pharmacological or not) to prevent new episodes. Despite this, some medicines (e.g., fludrocortisone and norepinephrine transport inhibitor) may reduce its recurrence. (Brignole et al., 2018; Lei, Raj, \& Sheldon, 2020). Regarding non-pharmacological approaches, the physical counter-pressure maneuver (i.e., isometric contraction of large muscle groups during the pre-syncope moment) has weak evidence, and the cardiac pacemaker efficacy in patients with bradycardia remains uncertain, but the closed-circuit stimulation has beneficial results. (Lopes da Cunha et al., 2019; Jensen, et al., 2020).

Conversely, vestibular physiotherapy (VP) based on exercises is effective in reducing the risk of falls and improving vertiginous symptoms, balance, and the emotional state of adults with chronic dizziness. (Kundakci et al., 2018). Body and mind exercises, such as yoga, are another approach with positive effects on the balance of healthy people. (Jeter et al., 2014). Despite this, the literature lacks data regarding the effects of VP and/or yoga in patients with VVS. Thus, the present case 
report aims to evaluate the effects of VP associated with yoga in a patient with VVS and complaints of dizziness and body imbalance.

\section{Methods}

\section{Type of study and ethical aspects}

This is a case report derived from an academic extension project that promotes VP for otoneurological patients at the Physiotherapy Department of the Federal University of Rio Grande do Norte (Brazil). The study was conducted according to the Resolution 466/12 of the National Health Council and the Declaration of Helsinki, and was approved by the research ethics committee of the institution (n. 3.305.800). The patient signed an informed consent form and the image authorization term.

\section{Procedures}

Sociodemographic, clinical, and otoneurological data were collected by an otoneurologist. Initial physiotherapy evaluation (EV1) assessed functionality, balance, gait, and quality of life. Right after the initial assessment, a personalized VP protocol focused on the patient's deficits was elaborated. The VP protocol was composed of 31 sessions, with a frequency of one to two times per week, and home-based exercises. The latter was performed daily and comprised the same outpatient exercises. Two reassessments were also conducted: one at the end of the VP program (EV2) and another after one year (EV3), totaling two years of follow-up.

\section{Functional assessment}

The dizziness intensity was assessed using the Numerical Rating Scale (NRS), with an interval from 0 to 10, in which zero was the absence of dizziness and 10 the most intense dizziness ever felt. (Jung et al., 2017). The quality of life was evaluated using the Brazilian version of the Dizziness Handicap Inventory (DHI), which addresses physical, functional, and emotional aspects in 25 questions. Higher scores reflect a worse quality of life. (Meirelles de Castro et al., 2006). The Dynamic Gait Index (DGI) and the modified Clinical Test of Sensory Interaction on Balance (mCTSIB) were used to assess the gait and static balance, respectively. The DGI comprises eight different gait tasks, in which higher scores represent better balance during gait. (Meirelles de Castro et al., 2006).

The Dynamic Gait Index (DGI) and the modified Clinical Test of Sensory Interaction on Balance (mCTSIB) were used to assess the gait and static balance, respectively. The DGI comprises eight different gait tasks, in which higher scores represent better balance during gait. (Meirelles de Castro et al., 2006). The mCTSIB consists of four different sensory conditions that assess the contribution of the vestibular, visual, and somatosensory systems to postural control. (Wrisley \& Whitney, 2004). The ability to sustain single-leg stance with eyes open and closed (on both the right and left lower limbs) and tandem stance were also evaluated.

\section{Rehabilitation protocol}

The VP consisted of personalized eye stabilization, oculomotor, habituation, and postural stabilization exercises (Chart 1), following the progression recommended by Alsalaheen et al. (2013). The physiotherapists conducted the exercises to monitor and promote patient safety, obtain potential results, and correct inappropriate postures (Figure 1). 
Chart 1. Information regarding the VP protocol.

\begin{tabular}{|c|c|c|}
\hline Exercise & Definition & Example \\
\hline Eye stabilization & $\begin{array}{c}\text { Cephalic movements with the target } \\
\text { fixed or in movement to promote } \\
\text { vestibulo-ocular reflex adaptation. }\end{array}$ & $\begin{array}{c}\text { RVOx1, RVOx2, reading with } \\
\text { cephalic movements. }\end{array}$ \\
\hline Oculomotor & $\begin{array}{c}\text { Performed with the eyes and aimed to } \\
\text { oculomotor re-education. }\end{array}$ & $\begin{array}{c}\text { Saccadic movements, vergence, } \\
\text { smooth pursuit. }\end{array}$ \\
\hline Habituation & $\begin{array}{c}\text { Exposure of the patient to movements, } \\
\text { positions, and situations that cause } \\
\text { vestibular symptoms and aim to } \\
\text { desensitization. }\end{array}$ & $\begin{array}{c}\text { Brandt-Daroff habituation } \\
\text { excises, reaching a target above } \\
\text { the head or at the feet level, lying } \\
\text { down, and sitting on the bed. }\end{array}$ \\
\hline Postural stabilization & $\begin{array}{c}\text { allenging circumstances to static } \\
\text { balance and gait to enhance visual and } \\
\text { somatosensory afferents. }\end{array}$ & $\begin{array}{c}\text { Romberg on foam, sustained } \\
\text { single-leg stance, tandem stance. }\end{array}$ \\
\hline
\end{tabular}

RVOx1: exercise to stabilize the X1 paradigm viewing; RVOx2: exercise to stabilize the X2 paradigm viewing. Source: Adapted from Herdman \& Whitney (2014).

The treatment for the cervical region included motor control training of the deep flexor muscles using visual feedback and manual therapy through manual myofascial release of the suboccipital (Figure 1), upper trapezius, supraspinatus, and levator scapulae muscles. The training of the deep cervical flexor muscles was performed in 4 sessions (i.e., one month) in the final phase of the treatment, and comprised 10 sustained contractions (10 seconds each), within an activation level of $24 \mathrm{mmHg}$ (determined using the Craniocervical Flexion Test), with an interval of 30 seconds between each contraction. The craniocervical flexion was controlled slowly and with the aid of an air pressure sensor (Stabilizer ${ }^{\mathrm{TM}}$, Chattanooga Group Inc., Chattanooga, TN) positioned below the occipital region (Figure 1). The contraction of the superficial cervical flexor muscles during this exercise was discouraged by the physiotherapists. (Jull et al., 2002).

Three months after the VP onset, the patient began to practice yoga in three different programs. The first program was directed to postures aiming to gain strength, balance, and flexibility and totaled 11 months (30 minutes, two to three times per week). The second program was performed for eight months, six to seven times per week (each session lasted 30 minutes), and comprised postures for relaxation, strength, balance, and flexibility. The third program was performed for three months (30 minutes six to seven times per week) and included postures for flexibility and balance. 
Research, Society and Development, v. 10, n. 1, e48210110633, 2021

(CC BY 4.0) | ISSN 2525-3409 | DOI: http://dx.doi.org/10.33448/rsd-v10i1.10633

Figure 1 - Personalized vestibular physiotherapy exercises and cervical region physiotherapy approach.
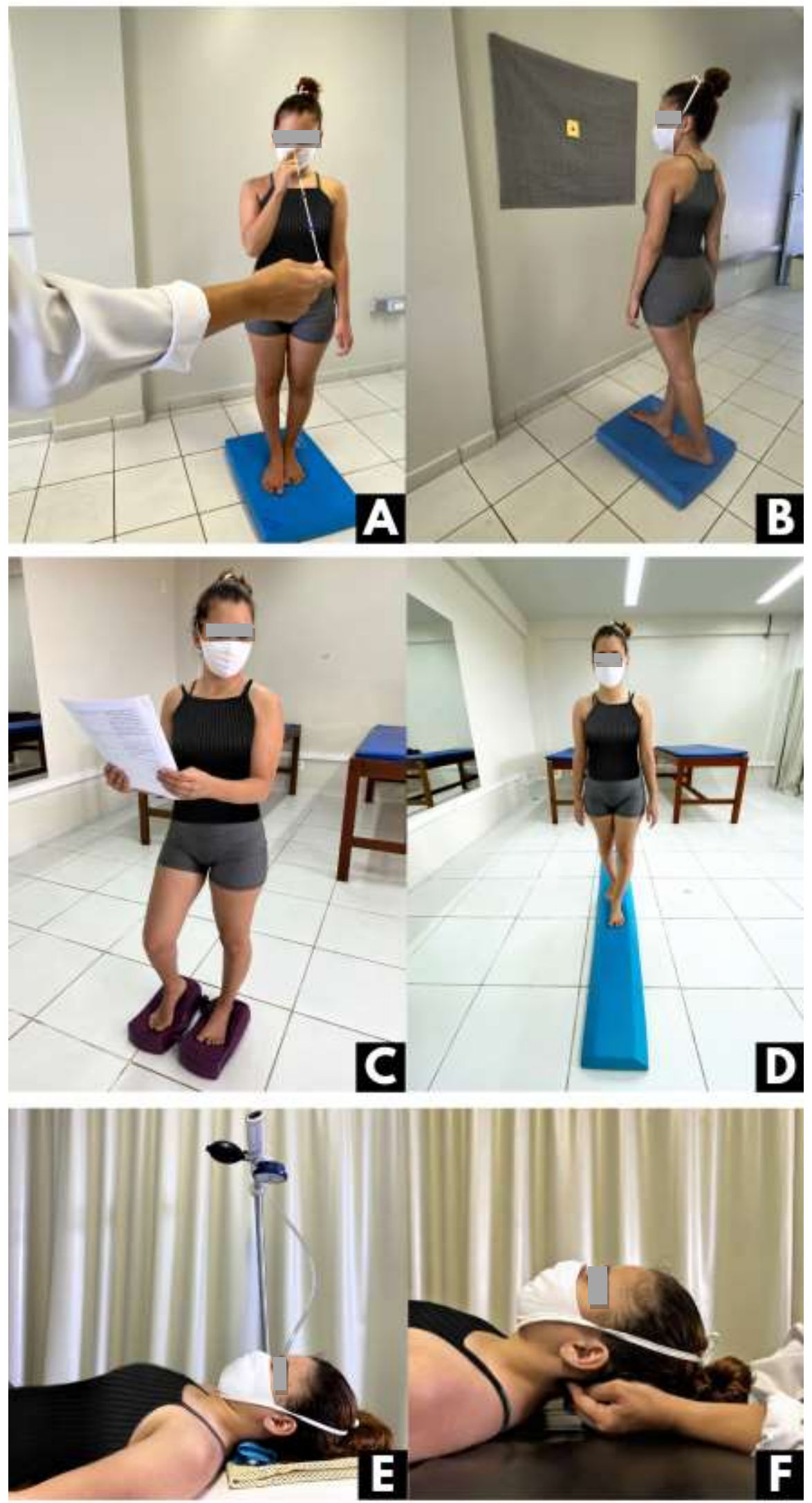

(A) Eye convergence exercise; (B) Balance training on an unstable surface associated with exercises to stabilize the X1 paradigm view (RVOx1) with visual conflict; (C) Dynamic visual acuity training on an unstable surface; (D) Tandem stance on an unstable surface; (E) Motor control training of deep flexor muscles using visual feedback with StabilizerTM; (F) Myofascial release of suboccipital muscles. Source: Authors. 


\section{Case Description}

Female patient, 22 years old, complaining of continuous vertigo for five years, and presence of oscillopsia, neurovegetative symptoms (sweating and nausea), aural fullness, and bilateral tinnitus. The dizziness initiated after an episode of intense stress and usually lasts one to seven days during crisis. The patient also reported a value of 3 in the NRS for dizziness at EV1 and 8 during crises.

Dizziness worsened with head movements, with no preferential side, and was accompanied by syncope during very intense episodes. The tinnitus was not always simultaneous in both ears and had non-pulsatile, intermittent, and alternating bilateral characteristics.

The patient had no comorbidities and was not using medications. The patient had no comorbidities and was not using medications.

Oculomotor evaluation (spontaneous and semi-spontaneous nystagmus, optokinetic reflex, saccadic movements, and skew deviation), head impulse test, cerebellar tests (finger-to-nose, heel-to-shin, and dysdiadochokinesia), Romberg test, Fukuda step test, Dix-Hallpike maneuver, and the roll-test were normal. Conversely, the smooth pursuit (presence of saccadic intrusion to the left), cancelled vestibular-ocular reflex (difficulty in focusing on the target), and convergence (29 centimeters) were altered. The video-head impulse test (VHIT) revealed hypofunction in the left anterior semicircular canal, with gain values close to normal (Figure 2).

The following audiological exams were performed: pure-tone and vocal audiometry were within normal limits, despite presenting an asymmetric curve slightly shifted toward lower frequencies; distortion-product otoacoustic emissions with normal bilateral patterns; and auditory brainstem evoked potentials (BAEP) within normal limits bilaterally. An MRI was requested due to the auditory asymmetry, and a vascular loop in the ostium of the left internal auditory canal was found.

Regarding the cervical evaluation, the patient reported myofascial pain with a reduced range of motion during left lateral inclination. Soft tissue was altered (i.e., presence of tender and trigger points) bilaterally in the upper trapezius, rhomboid, occipital, and levator scapulae muscles, as well as in the right supraspinatus.

The patient also reported imbalance while standing and during transfers and gait (with deviation to the left side). Difficulties in maintaining a tandem stance and during right and left single-leg stance with eyes closed were also observed. In the mCTSIB, the balance was altered only during the sensory condition with closed eyes and on an unstable surface (Table 1). Regarding balance during gait and the quality of life, the patient scored 20 in the DGI and 72 in the DHI test (24 in the physical domain, 32 in the functional domain, and 16 in the emotional domain).

The patient was treated only with symptomatic medication (meclizine, in case of severe dizziness) and referred to VP. 
Figure 2 - Audiological and otoneurological exams.

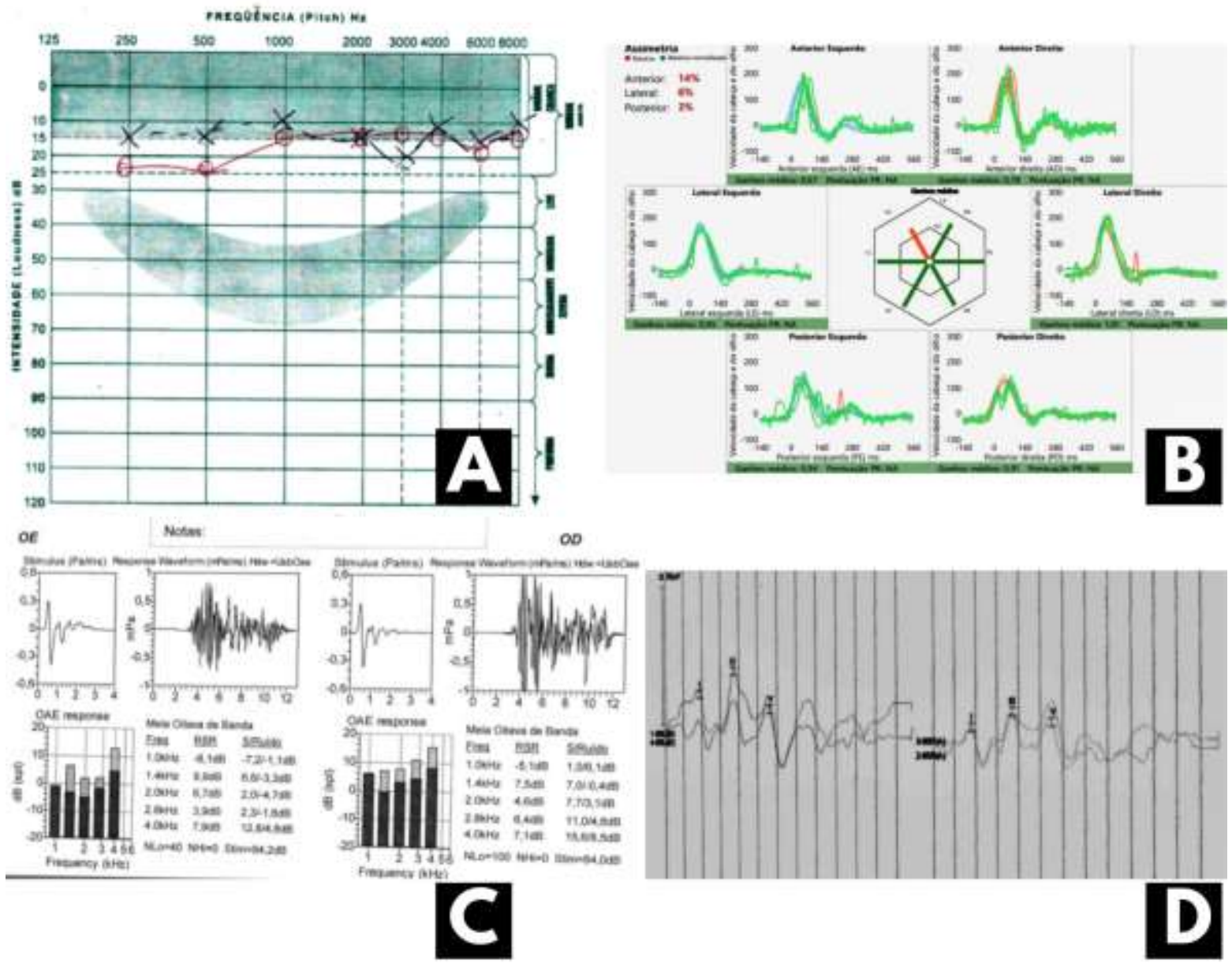

(A) pure-tone audiometry; (B)Video-Head impulse test; (C) Distortion-product otoacoustic emissions; (D) Brainstem Auditory Evoked Potential. Source: Authors.

The patient complained of weekly vertigo with a 20-minute duration; however, she reported no dizziness and no tinnitus or syncope episodes in EV2 (i.e., end of the VP program). The only complaint reported in EV3 (i.e., one year after the VP program) was vertigo of 1-2 minutes duration (frequency of every two weeks) with the same intensity as the previous assessment (EV2).

Gait imbalance with a shift to the right was observed in EV2; however, it was no longer present in EV3. No changes in mCTSIB, tandem stance, and single-leg stance with open and closed eyes were observed in EV2 and EV3. (Table 1). 
Table 1. Posture maintenance time during static balance tests.

\begin{tabular}{lccc}
\hline Tests & Time in EV1 (s) & Time in EV2 (s) & Time in EV3 (s) \\
\hline mCTSIB - OE/SS & 30 & 30 & 30 \\
mCTSIB - OE/US & 30 & 30 & 30 \\
mCTSIB - CE/SS & 30 & 30 & 30 \\
mCTSIB - CE/US & 2 & 30 & 30 \\
Tandem & 3 & 30 & 30 \\
RSS/OE & 30 & 30 & 30 \\
LSS/OE & 30 & 30 & 30 \\
RSS/CE & 4 & 30 & 30 \\
LSS/CE & 20 & 30 & 30 \\
\hline
\end{tabular}

EV1: assessment 1; EV2: assessment 2; EV3: assessment 3; s: seconds; mCTSIB: modified Clinical Test of Sensory Interaction and Balance; OE: open eyes; CE: closed eyes; SS: stable surface; US: unstable surface; RSS: right single-leg stance; LSS: left single-leg stance. Source: Authors.

The maximum DGI performance was obtained in EV3 (Figure 3), while the total DHI score reduced in EV2 (physical aspects: 12; functional aspects: 10; emotional aspects: 10) and EV3 (physical aspects: 12; functional aspects: 6; emotional aspects: 0) (Figure 4).

Figure 3 - Balance and gait measurements using the dynamic gait index (DGI).

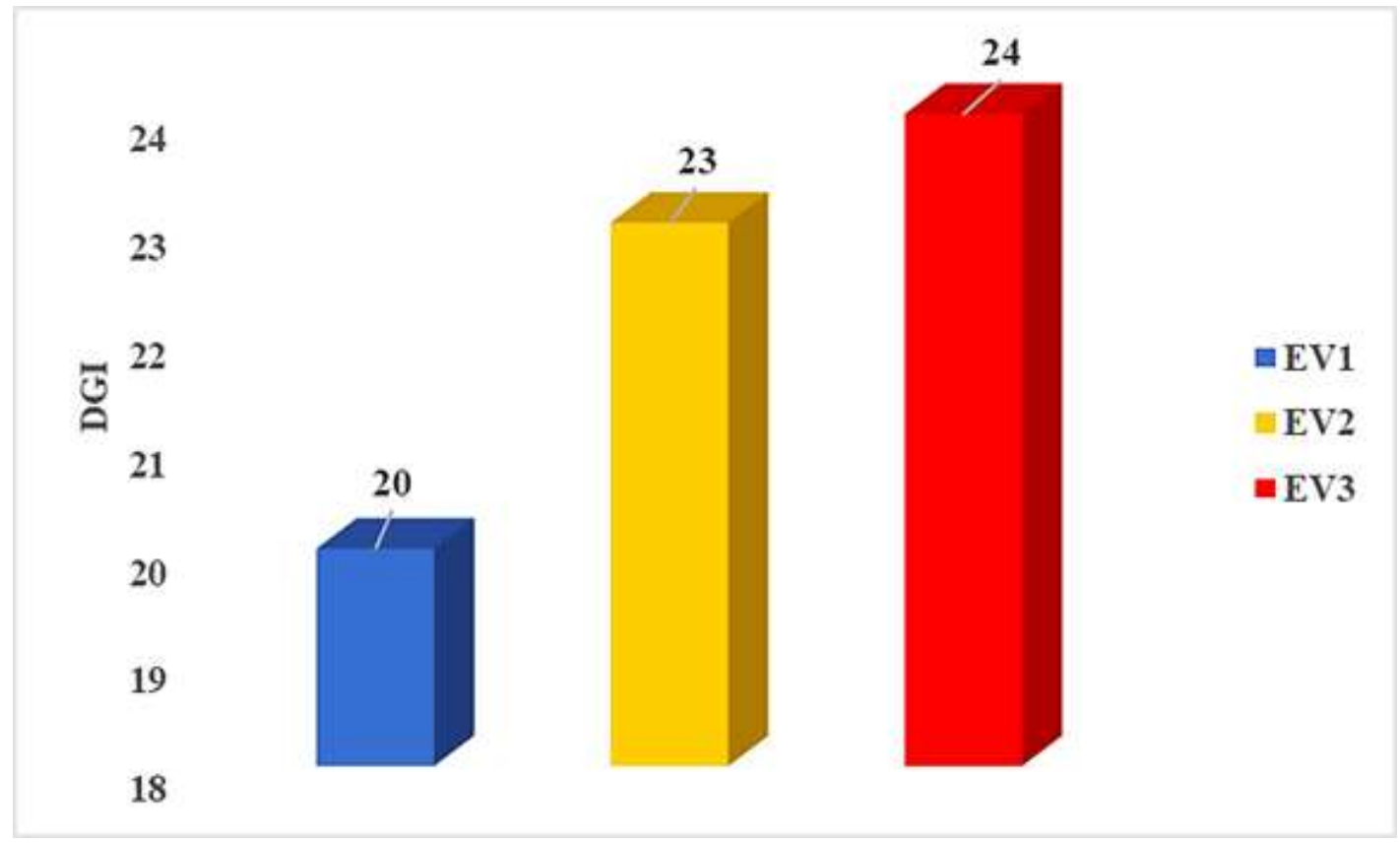

EV1: evaluation 1; EV2: evaluation 2; EV3: evaluation 3. Source: Authors. 
Saccadic movements, optokinetic reflex, canceled vestibular-ocular reflex, and skew deviation were not altered in EV2 and EV3; however, semi-spontaneous nystagmus was present, and convergence changed (11 centimeters) in EV2, both returning to normal values in EV3.

Range of motion during cephalic rotation and inclination for both sides was reduced in EV2, while only the right lateral inclination remained altered in EV3. The upper trapezius, rhomboid, suboccipital, and levator scapulae muscles presented tender points bilaterally in EV2 and EV3, except for the supraspinatus, which was remised in EV3.

Figure 4 - Quality of life using the Brazilian version of the Dizziness Handicap Inventory (DHI).

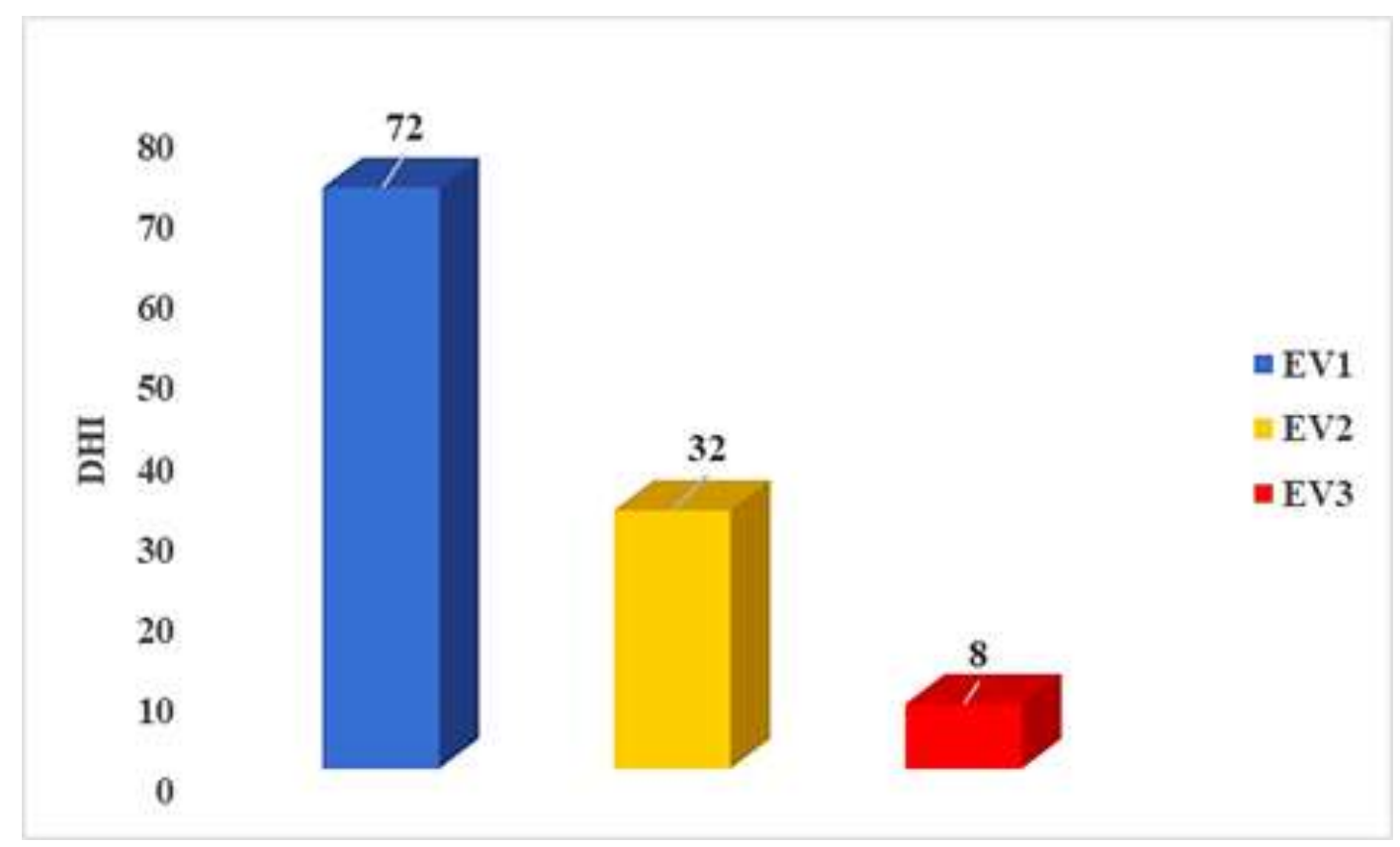

EV1: evaluation 1; EV2: evaluation 2; EV3: evaluation 3. Source: Authors.

\section{Discussion}

With a confirmed diagnosis of VVS, the evaluated patient sought otorhinolaryngological help complaining of continuous dizziness and other otoneurolo

The neurovascular disease can develop otoneurological symptoms, although the labyrinth is not the origin of the problem. (Azevedo, Barbisan, \& Silva, 2009). In this case report, the symptoms were complementary to the condition; however, the syncope referred to a non-labyrinthine condition. The dizziness symptoms started after an gical symptoms, such as bilateral tinnitus and aural fullness.The neurovascular disease can develop otoneurological symptoms, although the labyrinth is not the origin of the problem. (Azevedo, Barbisan, \& Silva, 2009). In this case report, the symptoms were complementary to the condition; however, the syncope referred to a non-labyrinthine condition. The dizziness symptoms started after an

Normal otoneurological examination and some findings were identified in the complementary tests, such as left labyrinthine hypofunction and vascular loop in the left internal auditory canal. We then initiated with a differential diagnosis of labyrinthine causes, according to the clinical characteristics and the altered complementary exams.

Although the patient had the classic Menière's Syndrome triad (i.e., dizziness, hearing loss, and tinnitus - Menière's Syndrome characteristics) (Lopez-Escamez et al., 2015), this diagnosis was discarded due to the dizziness characteristics (duration of days and persistent - it lasts up to 24 hours and is intermittent in Menière's Disease), the bilateral tinnitus, the patient's age (usually Menière's Disease affects older women), and the presence of consciousness loss during crises (drop 
attacks can occur in Menière's Disease, with a sudden fall but with no consciousness loss). The hypofunction observed during the VHIT, as already noted, had little clinical importance because its value was close to normal.

The observed vascular loop can be found in $1 / 3$ of asymptomatic patients (Parnes et al., 1990), due to anatomical variations in the internal auditory canal or the arteries location at the cerebellar angle. In cases in which the anatomical variation causes neural involvement, a syndrome called vestibular paroxysmia occurs, leading to short-term positional dizziness, pulsatile tinnitus, low-frequency hearing loss, and nerve conduction alteration, identified using the BAEP. (Jannetta, Møller, \& Møller, 1984). A good response to the treatment with anticonvulsants usually closes the diagnosis. The MRI of the evaluated patient presented this finding, but the clinical symptoms did not correspond exactly to vestibular paroxysmia since vertigo lasted for days and tinnitus was not pulsatile. Therefore, the MRI finding did not necessarily indicate the dizziness cause.

In light of these findings, all symptoms were attributed to VVS, which led us to initiate the VP program. A review showed that VP reduces the complaints of dizziness and imbalance of central and non-vestibular origin, although the level of evidence was not robust due to the heterogeneity and sample size of the studies. (Hansson, 2007). The VP was based on exercises to enhance the central nervous system compensation in the face of vestibular disorders. (Hoffer \& Balaban, 2011).

The results of the present case report demonstrated that the VP protocol associated with yoga led to the cessation of dizziness complaints, tinnitus, and syncope episodes. The literature points out that dizziness leads to important participation restrictions (Perez et al., 2001), and that VP is associated with improvements in the quality of life and intensity and frequency of symptoms. (Hillier \& McDonnell, 2016). Cervical myofascial release techniques were also used and may have influenced the tinnitus regression since the deactivation of cervical tender points promotes somatosensory tinnitus improvements. (Rocha \& Sanchez, 2012).

Most of the postural balance assessments were satisfactory, and improvements were observed in the test scores, especially those performed with low base of support and greater sensory conflict. This is the best condition to assess the vestibular system (Baydan, Yigit, \& Aksoy, 2020) since both the somatosensory and visual informations are reduced. This finding is in line with the literature that points out the VP benefits for treating postural instability in patients with chronic dizziness. (Kundakci et al., 2018). The concomitant Yoga practice may have also favored the established therapy since it is associated with greater postural control stabilization. (Kasse et al., 2014). A study involving individuals with Parkinson's disease showed that body and mind exercises improved postural instability and functional mobility. Yoga, in turn, increases body self-awareness associated with a relaxed mental state. (Kwok, Choi, \& Chan, 2016).

In addition to the VP effects, some complementary therapies (i.e., Yoga, Lian gong, and Tai Chi Chuan) are effective for individuals with dizziness, reducing anxiety and depression by promoting harmonization between the body and the mind. (Lopes et al., 2019). The DHI score reduced approximately 85\% between the first and the last assessment, indicating an improvement in the domains related to the influence of dizziness on the quality of life. As three points are considered the minimal clinically important difference for DHI (Friscia et al., 2014), a change of more than 50 points represented an important beneficial effect.

Segmental stabilization exercises in the cervical region were considered for the painful condition since the effectiveness of resistance training for deep cervical flexor muscles in individuals with chronic neck pain is well established in the literature. (Jull et al., 2009). However, it is possible that the four sessions performed at the end of the treatment did not influence pain intensity since the protocols for these muscles require greater exercise volume, usually 16 sessions. (Sikka et al., 2020). Despite the clinical improvement observed in several aspects, cervical pain was still present, which can be justified by the influence of psychosocial factors and the greater emphasis on the treatment of otoneurological and postural symptoms that led to greater disability by the patient. (Arvidsson et al., 2020). 
The study design can be considered a limitation; thus, it is not possible to generalize the results for the entire population with VVS. However, important points can be highlighted, such as the long-term effects of the rehabilitation program, the physical activity practice, and the body and mind harmony offered by Yoga.

\section{Final Considerations}

The VP program associated with Yoga showed positive results on clinical symptoms of dizziness, tinnitus, static balance, gait, and the quality of life of the patient with VVS. Thus, the therapeutic approach can be based not only on the pathophysiology but the patient's symptoms and functionality. Despite being a case report, this study is relevant for future research with larger sample sizes and adequate methodological quality since the interventions showed promising results.

\section{Acknowledgement}

This study received financial support by the Coordenação de Aperfeiçoamento de Pessoal de Nível Superior (CAPES/Brazil) (grant number 001).

\section{References}

Alboni, P. (2015). The different clinical presentations of vasovagal syncope. Heart, 101 (9), 674-678.

Alboni, P., Brignole, M., Menozzi, C., Raviele, A., Del Rosso, A., Dinelli, M., Bettiol, K., et al. (2004). Clinical spectrum of neurally mediated reflex syncopes. Europace, 6(1), 55-62.

Alsalaheen, B. A., Whitney, S. L., Mucha, A., Morris, L. O., Furman, J. M., \& Sparto, P. J. (2013). Exercise prescription patterns in patients treated with vestibular rehabilitation after concussion. Physiotherapy Research International, 18(2), 100-108.

Arvidsson, I., Gremark Simonsen, J., Lindegård-Andersson, A., Björk, J., \& Nordander, C. (2020). The impact of occupational and personal factors on musculoskeletal pain - A cohort study of female nurses, sonographers and teachers. BMC Musculoskeletal Disorders, 21(1), 621-638.

Azevedo, M. C. S., Barbisan, J. N., \& Silva, E. O. A. (2009). A predisposição genética na síncope vasovagal. Revista Da Associação Médica Brasileira, 55(1), 19-21.

Baydan, M., Yigit, O., \& Aksoy, S. (2020). Does vestibular rehabilitation improve postural control of subjects with chronic subjective dizziness? Plos One, 15(9), e0238436.

Brignole, M., Moya, A., De Lange, F. J., Deharo, J. C., Elliott, P. M., Fanciulli, A., Fedorowski, A., et al. (2018). ESC Guidelines for the diagnosis and management of syncope. European Heart Journal, 39(21), 1883-1948.

Lopes da Cunha, G. J., Rocha, B. M. L., Gomes, R. V., Silva, B. V., Mendes, G., Morais, R., Araújo, I. et al. (2019). A systematic review on recurrent cardioinhibitory vasovagal syncope: Does pacing therapy break the fall? Pacing and Clinical Electrophysiology, 42(10), $1400-1407$.

Meirelles de Castro, S., Perracini, M. R., \& Ganança, F. F. (2006). Versão brasileira do Dynamic Gait Index. Revista Brasileira de Otorrinolaringologia, $72(6), 817-825$

Fenton, A. M., Hammill, S. C., Rea, R. F., Low, P. A., \& Shen, W. K. (2000). Vasovagal syncope. Annals of Internal Medicine, 133(9), 714-725.

Friscia, L. A., Morgan, M. T., Sparto, P. J., Furman, J. M., \& Whitney, S. L. (2014). Responsiveness of self-report measures in individuals with vertigo, dizziness, and unsteadiness. Otology and Neurotology, 35(5), 884-888.

Ganzeboom, K. S., Mairuhu, G., Reitsma, J. B., Linzer, M., Wieling, W., \& Van Dijk, N. (2006). Lifetime cumulative incidence of syncope in the general population: A study of 549 Dutch subjects aged 35-60 years. Journal of Cardiovascular Electrophysiology, 17(11), 1172-1176.

Gracie, J., Newton, J. L., Norton, M., Baker, C., \& Freeston, M. (2006). The role of psychological factors in response to treatment in neurocardiogenic (vasovagal) syncope. Europace, 8(8), 636-643.

Grubb, B. P. (2005). Neurocardiogenic Syncope. New England Journal of Medicine, 352(10), 1004-1010.

Hansson, E. E. (2007). Vestibular rehabilitation - For whom and how? A systematic review. Advances in Physiotherapy, 9(3), 106-116.

Herdman, S., \& Whitney, S. (2014). Physical Therapy Treatment of Vestibular Hypofunction. In S. Herdman \& R. Clendaniel, Vestibular rehabilitation (4a ed, pp. 394-431.). Philadelphia: F.A. Davis Company.

Hillier, S., \& McDonnell, M. (2016). Is vestibular rehabilitation effective in improving dizziness and function after unilateral peripheral vestibular hypofunction? An abridged version of a Cochrane Review. European Journal of Physical and Rehabilitation Medicine, 52(4), 541-556. 
Hoffer, M. E., \& Balaban, C. D. (2011). Vestibular rehabilitation: Ready for the Mainstream. NeuroRehabilitation, $29(2), 125$.

Jannetta, P. J., Møller, M. B., \& Møller, A. R. (1984). Disabling Positional Vertigo. New England Journal of Medicine, 310(26), $1700-1705$.

Jensen, J. L., Ohshimo, S., Cassan, P., Meyran, D., Greene, J., Ng, K. C., Singletary, E., et al. (2020). Immediate Interventions for Presyncope of Vasovagal or Orthostatic Origin: A Systematic Review. Prehospital Emergency Care, 24(1), 64-76.

Jeter, P. E., Nkodo, A. F., Moonaz, S. H., \& Dagnelie, G. (2014). A systematic review of yoga for balance in a healthy population. Journal of Alternative and Complementary Medicine, 20(4), 221-232.

Jull, G. A., Falla, D., Vicenzino, B., \& Hodges, P. W. (2009). The effect of therapeutic exercise on activation of the deep cervical flexor muscles in people with chronic neck pain. Manual Therapy, 14(6), 696-701.

Jull, G., Trott, P., Potter, H., Zito, G., Niere, K., Shirley, D., Emberson, J., et al. (2002). A randomized controlled trial of exercise and manipulative therapy for cervicogenic headache. Spine, 27(17), 1835-1842.

Jung, F. C., Mathew, S., Littmann, A. E., \& Macdonald, C. W. (2017). Clinical decision making in the management of patients with cervicogenic dizziness: A case series. Journal of Orthopaedic and Sports Physical Therapy, 47(11), 874-884.

Kasse, C., Prado, E., Raso, V., \& Scharlach, R. (2014). Hatha yoga on body balance. International Journal of Yoga, 7(2), 133.

Kenny, R. A., Bhangu, J., \& King-Kallimanis, B. L. (2013). Epidemiology of Syncope/Collapse in Younger and Older Western Patient Populations. Progress in Cardiovascular Diseases, 55(4), 357-363.

Kuhmmer, R., Lazzaretti, R. K., \& Zimerman, L. I. (2008). Artigo de revisão síncope vasovagal e suplementação de sal. Revista HCPA, $28(2), 110-115$.

Kundakci, B., Sultana, A., Taylor, A. J., \& Alshehri, M. A. (2018). The effectiveness of exercise-based vestibular rehabilitation in adult patients with chronic dizziness: A systematic review. F1000 Research, 5(7), 276-288.

Kwok, J. J. Y. Y., Choi, K. C., \& Chan, H. Y. L. (2016). Effects of mind-body exercises on the physiological and psychosocial well-being of individuals with Parkinson's disease: A systematic review and meta-analysis. Complementary Therapies in Medicine, 29, 121-131.

Lei, L. Y., Raj, S. R., \& Sheldon, R. S. (2020). Pharmacological norepinephrine transporter inhibition for the prevention of vasovagal syncope in young and adult subjects: A systematic review and meta-analysis. Heart Rhythm, 17(7), 1151-1158.

Lopes, A. L., Lemos, S. M. A., Figueiredo, P. H. S., \& Santos, J. N. (2019). Impact of lian gong on the quality of life of individuals with dizziness in primary care. Revista de Saude Publica, 53, 73.

Lopez-Escamez, J. A., Carey, J., Chung, W.-H., Goebel, J. A., Magnusson, M., Mandalà, M., Newman-Toker, E., et al. (2015). Diagnostic criteria for Menière's disease. Journal of Vestibular Research, 25(1), 1-7.

Mathias, C. J., Deguchi, K., \& Schatz, I. (2001). Observations on recurrent syncope and presyncope in 641 patients. Lancet, $357(9253)$, $348-353$.

Moya, A., Sutton, R., Ammirati, F., Blanc, J. J., Brignole, M., Dahm, J. B., Deharo, J., et al. (2009). Guidelines for the diagnosis and management of syncope (version 2009). European Heart Journal, 30(21), 2631-2671.

Parnes, L. S., Shimotakahara, S. G., Pelz, D., Lee, D., \& Fox, A. J. (1990). Vascular relationships of the vestibulocochlear nerve on magnetic resonance imaging. The American Journal of Otology, 11(4), 278-281.

Perez, N., Garmendia, I., García-Granero, M., Martin, E., \& García-Tapia, R. (2001). Factor analysis and correlation between Dizziness Handicap Inventory and Dizziness Characteristics and Impact on Quality of Life Scales. Acta Oto-Laryngologica, Supplement, 545, $145-154$.

Rocha, C. B., \& Sanchez, T. G. (2012). Efficacy of myofascial trigger point deactivation for tinnitus control. Brazilian Journal of Otorhinolaryngology, 78(6), 21-26.

Sikka, I., Chawla, C., Seth, S., Alghadir, A. H., \& Khan, M. (2020). Effects of Deep Cervical Flexor Training on Forward Head Posture, Neck Pain, and Functional Status in Adolescents Using Computer Regularly. BioMed Research International, 2020.

Soteriades, E. S., Evans, J. C., Larson, M. G., Chen, M. H., Chen, L., Benjamin, E. J., \& Levy, D. (2002). Incidence and Prognosis of Syncope. New England Journal of Medicine, 347(12), 878-885.

Van Dijk, N., Sprangers, M. A., Boer, K. R., Colman, N., Wieling, W., \& Linzer, M. (2007). Quality of Life Within One Year Following Presentation After Transient Loss of Consciousness. American Journal of Cardiology, 100(4), 672-676.

Wrisley, D. M., \& Whitney, S. L. (2004). The Effect of Foot Position on the Modified Clinical Test of Sensory Interaction and Balance. Archives of Physical Medicine and Rehabilitation, 85(2), 335-338. 